\title{
AFTERSHOCK SEQUENCE OF THE 3 DECEMBER 1988 PASADENA EARTHQUAKE
}

\author{
By Kuo-Fong Ma and Hiroo Kanamori
}

\begin{abstract}
The Pasadena earthquake $\left(M_{L}=4.9\right)$ of 3 December 1988 occurred at a depth of $16 \mathrm{~km}$, probably on the Santa Monica - Raymond fault, which is recognized as one of the most important faults in the Los Angeles basin for its potential seismic hazard. Prior to this event, no earthquake larger than magnitude $\mathbf{4}$ had been recorded since 1930 in this area. High-quality seismograms were recorded with the Pasadena very broadband (VBB) system (IRIS-TERRAscope station) not only for the mainshock but also for the aftershocks at epicentral distances of 3 to $4 \mathrm{~km}$. We determined the focal mechanisms of 9 aftershocks using these data; for most of the aftershocks, the first-motion data are too sparse to determine the mechanism. We combined the first-motion data and the waveform data of $P, S V$, and $S H$ waves recorded with the VBB instrument to determine the mechanism and seismic moment of nine aftershocks. The average orientations of the $P$ and $T$ axes of the aftershocks are consistent with the strike of the Raymond fault. The ratio of the logarithm of cumulative seismic moment of aftershocks to that of the seismic moment of the mainshock is significantly smaller than commonly observed.
\end{abstract}

\section{INTRODUCTION}

The Pasadena earthquake $\left(M_{L}=4.9\right)$ occurred on 3 December 1988 at a depth of $16 \mathrm{~km}$ nearly directly beneath the Pasadena station. No earthquake with $M_{L}>4$ had been recorded since 1930 in this area. High-quality seismograms were recorded with the broadband Pasadena IRIS-TERRAscope system for the mainshock and nine aftershocks. Since the station is only about $4 \mathrm{~km}$ from the mainshock epicenter, these records are relatively free from contamination by propagation path effects.

Figure 1a shows the locations of the mainshock and the aftershocks taken from the catalog of the Caltech-USGS Southern California Seismic Network. Magistrale (1990) also determined the location of these events using a 3-D structure for the Los Angeles basin, which resulted in generally good agreement with that from the catalog. Figure 1a includes earthquakes that occurred during the period 1 January 1988 to 1 July 1990. Jones et al. (1990) obtained the focal mechanisms determination from the first-motion polarities. They showed that the mechanisms of the mainshock and four aftershocks, which are large enough to allow mechanisms of the mainshock and the four aftershocks indicate left-lateral strike-slip motions on an east-northeast-striking fault and suggest that the Pasadena earthquake occurred on the Santa Monica-Raymond fault, which has been recognized as one of the important faults in the Los Angeles basin. Since the entire extent of the Santa Monica-Raymond fault runs through the densely populated part of the Los Angeles basin, a large earthquake on this fault can cause a major seismic hazard. Kanamori et al. (1990) estimated the stress drop of the mainshock to be an order of $1 \mathrm{kbar}$, which is significantly higher than that of most large earthquakes. 
In view of these unique characteristics of the Pasadena earthquake, we determined the focal mechanisms of the aftershocks. Since the first-motion data for the aftershocks are too sparse to determine the mechanisms using the conventional first-motion method, we applied an inversion method to the broadband waveform data observed at Pasadena to determine the focal mechanisms. Since the epicentral distance is very short, $P$ and $S$ pulses can be inverted to determine the seismic moment and three fault parameters (dip, rake, and strike) using the method described by Kanamori (1989).

\section{DATA}

Fifteen aftershocks were recorded by the Caltech-USGS Southern California Seismic Network during the period from 3 to 31 December 1989 in the area. Of these, nine events were recorded at the Pasadena station (Table 1). We rotated
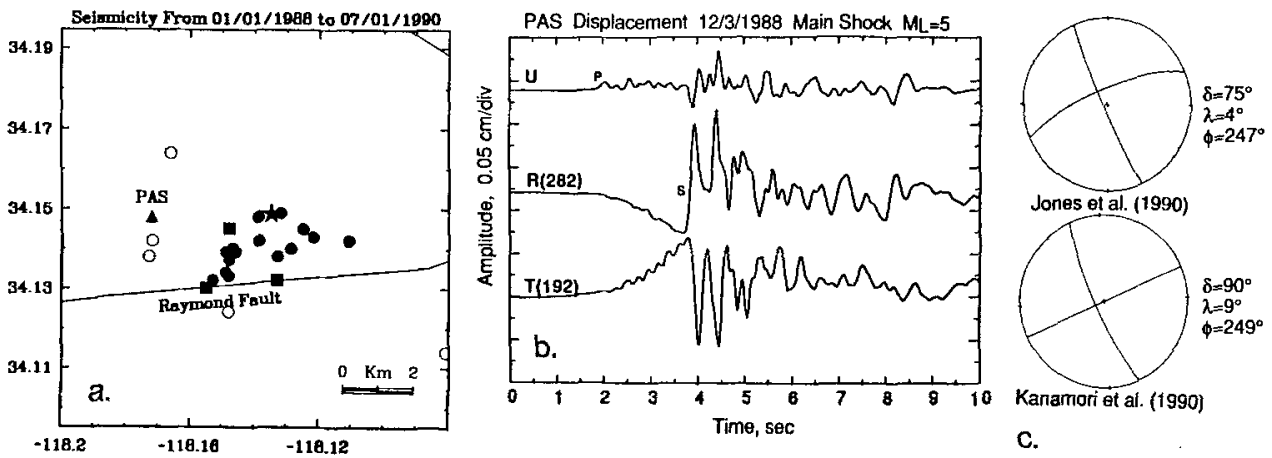

FIG. 1. (a) Seismicity before and after the 3, December 1988 Pasadena earthquake for the period from 1988 to July 1990 from the catalog of the Caltech-USGS Southern California Seismic Network. The open circles, solid circles, and solid squares indicate the foreshocks, the aftershocks from 3 to 31, December 1988, and the other aftershocks, respectively. The star and the triangle indicate the mainshock and the Pasadena station, respectively. (b) Rotated displacement records of the 3 December 1988, Pasadena earthquake obtained from the low-gain channel of the Pasadena system (high-pass-filtered at $5 \mathrm{sec}$ ). (c) The mechanisms of the mainshock determined by Jones et al. (1990) from the first-motion data and by Kanamori et al. (1990) using the waveform data.

TABLE 1

The Origin Time, Location, Fualt Parameters, and Seismic Moment of the Mainshock and Nine Aftershocks of the Pasadena Earthquake Sequence

\begin{tabular}{rccccccrrr}
\hline No. & $\begin{array}{c}\text { Date } \\
(\mathrm{y} / \mathrm{m} / \mathrm{d})\end{array}$ & Time & $\begin{array}{c}\text { Latitude } \\
\left({ }^{\circ} \mathrm{N}\right)\end{array}$ & $\begin{array}{c}\text { Longitude } \\
\left({ }^{\circ} \mathrm{W}\right)\end{array}$ & $\begin{array}{c}Z \\
(\mathrm{~km})\end{array}$ & \multicolumn{1}{c}{ Dip } & Rake & Strike & \multicolumn{1}{c}{$\begin{array}{c}M_{0} \\
\left(10^{19}\right. \\
\text { dyne-cm })\end{array}$} \\
\hline 0 & $88 / 12 / 03$ & 1138 & 34.149 & 118.135 & 15.4 & 90.0 & 9.0 & 249.0 & $24000-46000^{*}$ \\
1 & $88 / 12 / 03$ & 1149 & 34.139 & 118.154 & 15.5 & 61.2 & 26.8 & -98.9 & 2.58 \\
2 & $88 / 12 / 03$ & 1156 & 34.145 & 118.133 & 15.2 & 68.8 & 11.0 & -110.5 & 4.68 \\
3 & $88 / 12 / 03$ & 1208 & 34.156 & $\mathbf{1 1 8 . 1 2 7}$ & $\mathbf{1 5 . 9}$ & 45.4 & $\mathbf{1 1 . 1}$ & 73.9 & 2.06 \\
4 & $88 / 12 / 03$ & 1213 & 34.142 & $\mathbf{1 1 8 . 1 4 8}$ & $\mathbf{1 4 . 3}$ & 72.1 & 37.9 & -131.3 & 10.40 \\
5 & $88 / 12 / 03$ & 1215 & 34.141 & $\mathbf{1 1 8 . 1 4 8}$ & $\mathbf{1 5 . 0}$ & 88.0 & -6.2 & $\mathbf{4 5 . 4}$ & 2.54 \\
6 & $88 / 12 / 03$ & 1336 & 34.158 & $\mathbf{1 1 8 . 1 2 7}$ & $\mathbf{1 6 . 5}$ & $\mathbf{5 8 . 0}$ & $\mathbf{1 0 . 2}$ & $\mathbf{7 2 . 2}$ & 1.22 \\
7 & $88 / 12 / 03$ & 1446 & 34.142 & $\mathbf{1 1 8 . 1 4 6}$ & $\mathbf{1 4 . 5}$ & $\mathbf{8 5 . 8}$ & 24.6 & -109.3 & 0.76 \\
8 & $88 / 12 / 04$ & 0801 & 34.145 & $\mathbf{1 1 8 . 1 3 5}$ & $\mathbf{1 5 . 1}$ & 82.8 & $-\mathbf{9 . 2}$ & 44.3 & 1.74 \\
9 & $88 / 12 / 08$ & 0251 & 34.157 & $\mathbf{1 1 8 . 1 1 3}$ & $\mathbf{1 6 . 4}$ & 21.7 & $\mathbf{1 9 . 4}$ & 85.1 & 4.38 \\
\hline
\end{tabular}

*Kanamori et al. (1990). 
the broadband records into the transverse and radial components and deconvolved them with the instrument response to obtain ground motion displacement records. In order to remove the large microseismic noise with periods of 4 to $8 \mathrm{sec}$, we high-pass filtered the records at $3 \mathrm{sec}$. Figure $1 \mathrm{~b}$ shows the displacement record for the mainshock, and Figure 1c shows the mechanisms determined by Jones et al. (1990) from the first-motion data and by Kanamori et al. (1990) using the waveform data. Figure 2 shows the displacement waveforms of the aftershocks in three groups. The events in group 1 (Fig. 2a; events 2,7 , and 8) are very similar to the mainshock in waveform. They show a small upward $P$-wave motion, and an $S$ wave with negative (clockwise around the epicenter) transverse component and positive (away from the epicenter) radial component. This similarity suggests that the mechanisms of these events are similar of that of the mainshock. The events in group 2 (Fig. 2b; events 3,6 , and 9) have a downward $P$ wave and an $S$ wave with negative transverse and radial components. Group 3 (Fig. 2c; events 1, 4, and 5) has three events with very complex $S H$ waveforms, suggesting that the Pasadena station is located near the node of the radiation pattern of $S H$ waves. In general, the waveforms of $P$ and $S V$ waves of group 3 are more similar to those of group 1 than group 2 .
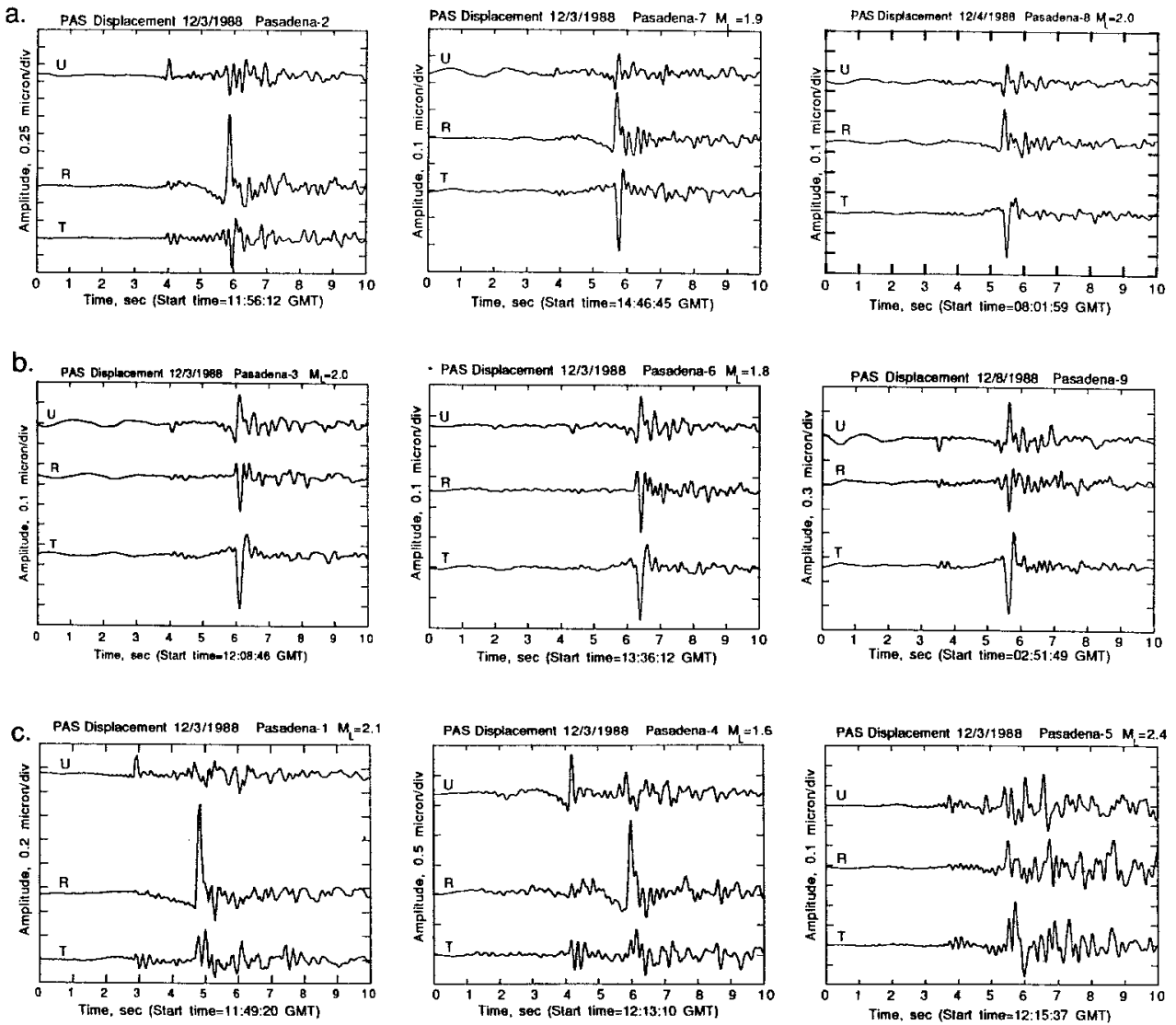

Fig. 2. Rotated displacement records of the 9 aftershocks in 3 groups: (a) Group 1: events 2, 7, and 8 ; (b) group 2: events 3,6 , and 9 ; (c) group 3 : events 1,4 , and 5 . The amplitude scale indicates the true ground motion amplitudes in microns 


\section{Method}

We used the method described in Kanamori (1989) and Kanamori et al. (1990) to determine the seismic moment and fault parameters (dip, rake, and strike). The $P, S V$, and $S H$ far-field displacements, $U_{r}, U_{\theta}$, and $U_{\phi}$, from a double-couple point source are given by

$$
\left[\begin{array}{c}
U_{r} \\
U_{\theta} \\
U_{\phi}
\end{array}\right]=\frac{M_{0} s(t)}{4 \pi \rho r \alpha^{3}}\left[\begin{array}{c}
R^{P} \\
(\alpha / \beta)^{3} R^{S V} \\
(\alpha / \beta)^{3} R^{S H}
\end{array}\right]
$$

where $s(t)$ and $M_{0}$ are the unit moment rate function and the seismic moment, respectively. Here, $\rho, \alpha$, and $\beta$ are density, $P$ velocity, and $S$ velocity, and $R^{P}$, $R^{S V}$, and $R^{S H}$ are $P$-wave, $S V$-wave, and $S H$-wave radiation patterns, respectively. The radiation patterns are functions of the fault parameters: dip $\delta$, rake $\lambda$, and strike $\phi$. We use (1) to determine $M_{0}, \delta, \lambda$, and $\phi$ from $U_{r}, U_{\theta}$, and $U_{\phi}$ estimated from the observed $P, S V$, and $S H$ amplitudes and polarities.

Let $U_{P}, U_{S V Z}, U_{S V R}$, and $U_{S H}$ be the displacements of the $P$ wave on the vertical component, the $S V$ wave on the vertical component, the $S V$ wave on the radial component, and the $S H$ wave on the tangential component, respectively, observed at the free surface. If we ignore the $P-S V$ conversion at the free surface, then

$$
\begin{aligned}
& U_{r}=U_{P} /\left(2 \cos i_{0}\right), \\
& U_{\theta}=U_{S V Z} /\left(-2 \sin i_{o}\right)=U_{S V R} /\left(2 \cos i_{0}\right), \\
& U_{\phi}=U_{S H} / 2,
\end{aligned}
$$

where $i_{0}$ is the incidence angle. The free-surface effect is approximated by a factor of 2 of amplification of the incidence wave. Since these events are very close to the station, this approximation is satisfactory. If $P-S V$ conversion at the free surface is considered, $U_{S V Z}$ and $U_{S V R}$ become more complex functions of the incidence angle. Since the effect of the free surface is generally smaller on the vertical component than on the radial component, we usually estimated $U_{\theta}$ from the vertical component. However, when $U_{S V Z}$ is too small to measure, we used $U_{S V R}$ to estimate $U_{\theta}$.

Because the number of parameters, 4 , is larger than the number of data, 3 , in equation (1), the solution is nonunique. We obtained the solution combining the waveform and first-motion data as follows.

Although the solution of equation (1) is nonunique, we can determine the range of allowable solutions that explain the observed amplitudes and polarities of $P, S V$, and $S H$ waves. Figure 3 shows the loci of the $P$ and $T$ axes (hereafter called the inversion $P-T$ loci) of the allowable solutions determined by inverting equation (1). Any solution with a pair of $P$ and $T$ axes on the loci yields the correct amplitudes and polarities of $P, S V$, and $S H$ waves.

Next we analyzed the first-motion data using the program FPFIT (Reasenberg and Oppenheimer, 1985). The available first-motion data recorded by the Caltech-USGS Southern California Seismic Network of the nine aftershocks are shown in Figure 3 by equal area projection of the lower hemisphere. Because the magnitudes of the aftershocks are in the range of 1.5 to 2 , the number of 


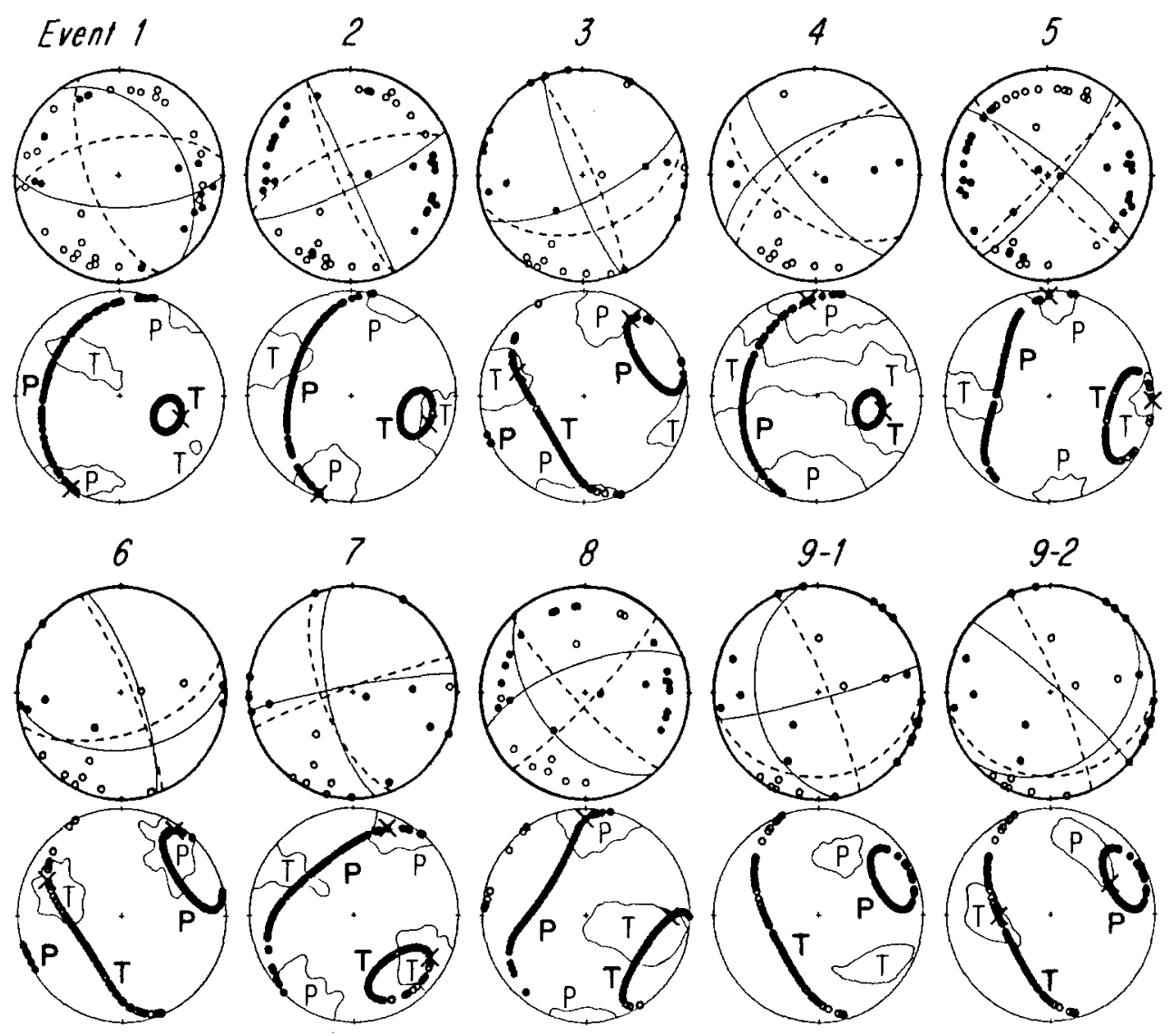

FIG. 3. The first-motion data recorded by the Caltech-USGS Southern California Seismic Network and the focal mechanisms determined from the first-motion data alone (solid curves) and the combined (first-motion and waveform) data (dashed curves) of the nine aftershocks of the 1988 Pasadena earthquake. The figure beneath the first-motion data shows the inversion $P-T$ loci (heavy curve with bold face letters) and the first-motion $P$-T ranges. The cross symbols indicate the $P$ and $T$ axes of our preferred solution.

first-motion data available is small. For some events, compressional and dilatational first motions are mixed, suggesting ambiguous beginning of the first motion. The program FPFIT uses a grid-search procedure to find a mechanism by minimizing the normalized, weighted sum of the discrepancies between the observed and theoretical polarity at each station. The program also determines the ranges of $P$ and $T$ axes of mechanisms that fit the first-motion data equally well. These ranges, here called the first-motion $P$ - $T$ ranges, are shown in Figure 3. Since the quality of the first-motion data is limited, the allowable $P-T$ ranges are generally large. Any solution in these ranges are considered acceptable. If the inversion $P$ - $T$ loci pass through the first-motion $P-T$ ranges, any solution for which the $P$ and $T$ axes lie in the overlapping region can satisfy both the first-motion and waveform data. If the inversion $P-T$ loci do not pass through the first-motion $P-T$ ranges, we chose a point on the inversion $P-T$ loci that is closest to the first-motion $P$ - $T$ ranges. Figure 3 shows the points we chose this way and the resulting solutions (dashed curve); these solutions are compared with those (solid curve) picked by FPFIT using the first-motion data alone. 


\section{Results}

For event 1 , the inversion $T$ axis locus does not pass through the first-motion $T$-axis range. This means that no solution can explain both the first-motion and waveform data simultaneously. We chose a mechanism with the $P$ axis located on the inversion $P$-axis locus and in the middle of the first-motion $P$-axis range as the solution. As shown in the mechanism diagram, this solution fits the first-motion data satisfactorily.

For event 9, two mechanisms are obtained from the first-motion data. However, the waveform data are consistent only with the mechanism with a low-angle plane dipping southeast (second solution in Fig. 3).

Considering the ambiguities in the first-motion data, the mechanisms for other events thus determined are in general consistent with the first-motion data. Some first-motion data are inconsistent, but, for these small events, first motion is not always distinct, and some inconsistency is acceptable.

To illustrate the sensitivity of the waveform to the mechanism, we compared the synthetic waveforms of event 8 , for instance, computed for the mechanism determined by the first-motion data only and by inversion. The waveform for the mechanism determined from the first-motion data (Fig. 4a) does not match the observed (Fig. 2), while the waveforms computed for the mechanism obtained by inversion (Fig. $4 \mathrm{~b}$ ) have the correct $P$ to $S H$ ratio. The waveform of $S V$ component is not explained very well, however. As mentioned earlier, the inversion is done using the first half cycle of the vertical component. The amplitude of the radial component is not used in the inversion. The vertical-toradial ratio is solely determined by the incidence angle. Also the $S V$ waveform on the vertical component is double-sided. This is probably due to $S V$ - $P$ interaction caused by some structures near the surface. We have not been able to explain this feature satisfactorily with a half-space or a layered half-space model. In our inversion, only gross amplitude ratio and polarity of $P, S V$, and $S H$ waves are used, and the second half cycle of the $S V$ wave is not used. For some events, a small oscillatory $P$ wave is observed on the transverse component. This might be due to structural hetrogeneity near the Pasadena station. The details of these features are unknown.

Figure 5a shows the spatial distribution of the mainshock and the aftershocks of the Pasadena earthquake sequence with focal mechanisms shown by equal area projections of the lower focal hemisphere. The locations are taken from Magistrale (1990). For group 1, the solutions thus obtained are similar to that of the mainshock. This is not surprising in view of the similarity of the waveforms. These solutions are in general consistent with the first-motion data with steeply dipping planes. The average orientations of $P$ and $T$ axes are in southwest-northeastern and southeastern directions, respectively. For group 2, the solutions were slightly different from that of the mainshock. One of the nodal planes is shallowly dipping to the south, especially for event 9 . The $P$ and $T$ axes have the average orientation of northeast and northwest, respectively. Since the waveforms of the events in group 3 are complex, the solution is less reliable than that for the events in groups 1 and 2 . The mechanism for event 5 is very similar to that of mainshock, although the $S H$ wave is almost on the node. The average orientations of $P$ and $T$ axes are similar to those of group 1. The $P$ and $T$ axes of these events are shown in Figure $5 \mathrm{~b}$.

The overall waveform similarity of events in group 1, group 3, and, to a lesser extent, group 2 to that of the mainshock suggests that the mechanisms of the 

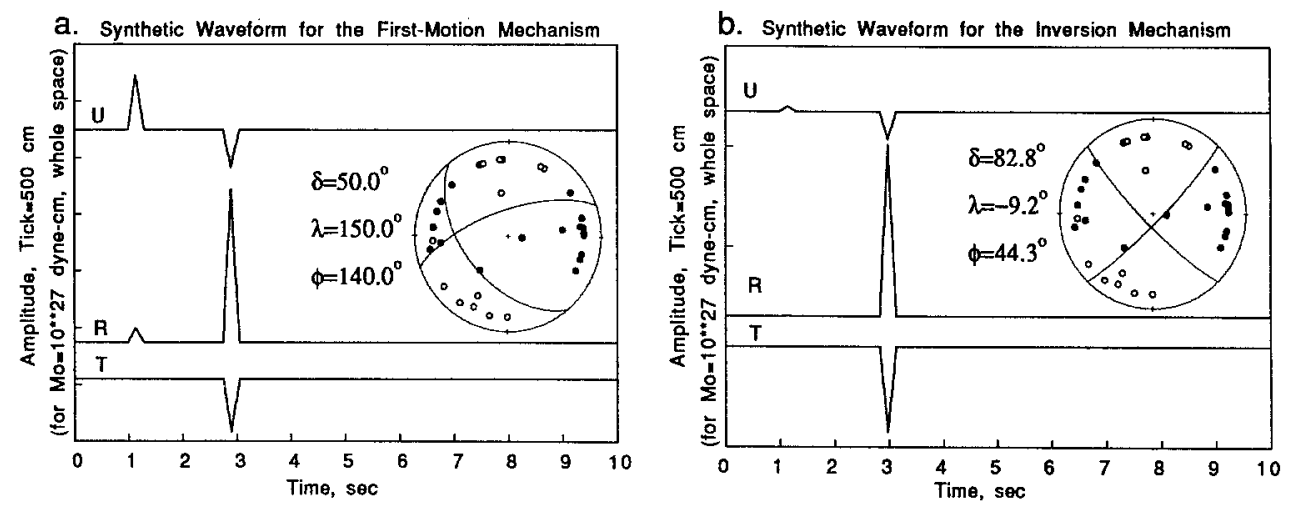

FIG. 4. (a) The mechanism obtained from the first-motion data of event 8 and the corresponding synthetics. (b) The mechanism obtained from the combined (waveform and first-motion) data of event 8 and the corresponding synthetics.
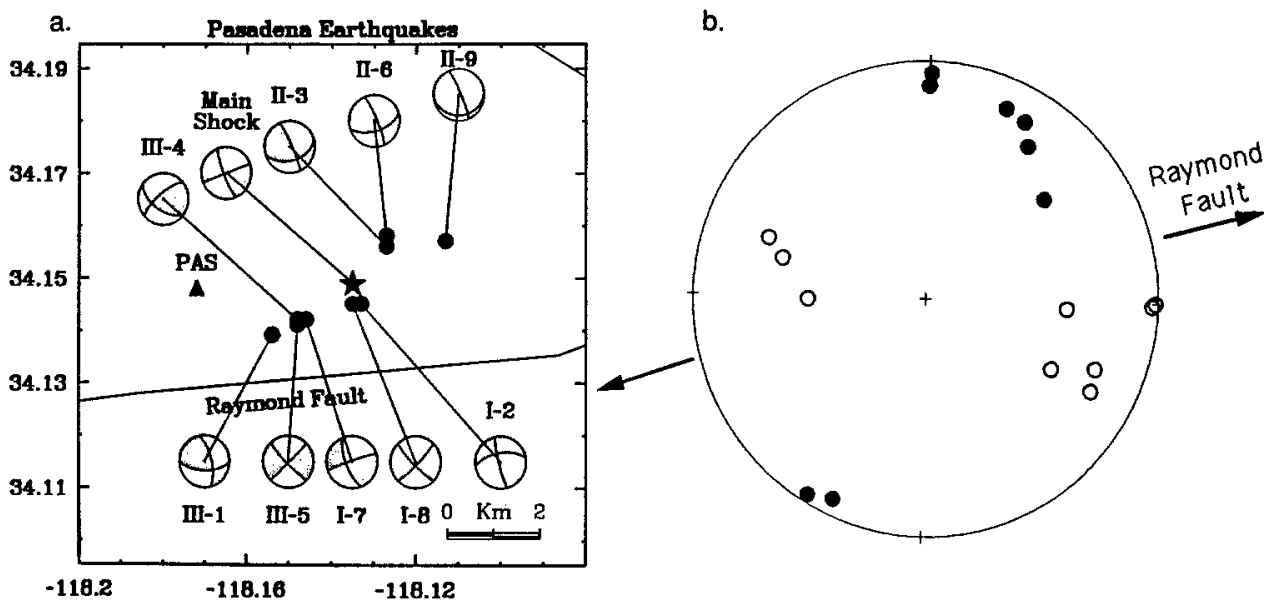

FIG. 5. (a) The spatial distribution of the mainshock and the aftershocks of the Pasadena earthquake sequence with focal mechanisms shown by equal-area projections of the lower focal hemisphere with the locations from Magistrale (1990). (b) Equal-area projection of the $P$ and $T$ axes on the lower hemisphere. The solid circles and open circles indicate $P$ and $T$ axes, respectively. The arrows indicate the average strike, $N 75^{\circ} \mathrm{E}$, of the Raymond fault.

aftershock are similar to that of the mainshock, and the result shown in Figure $5 \mathrm{a}$ is reasonable. The average orientations of the $P$ and $T$ axes of the aftershocks (Fig. 5b) are consistent with the strike of the Santa Monica-Raymond fault (strike of $\mathrm{N} 65^{\circ} \mathrm{E}$ to $\mathrm{N} 85^{\circ} \mathrm{E}$ ), in aggreement with Jones et al. (1990).

The focal mechanisms and seismic moments of the aftershocks of the Pasadena earthquake thus determined are listed in Table 1. A remarkable feature of this sequence is that the aftershocks are very few and small. In order to demonstrate this, we compared the Pasadena earthquake sequence to 12 earthquake sequences in California shown in Table 2 and Figure 6. We calculated the cumulative aftershock seismic moment $\left(\sum M_{0 A}\right)$ for these events. Except for the Pasadena earthquake sequence, the seismic moments of the aftershocks of the other events are estimated using the empirical relations, $\log M_{0}=1.5 M_{L}+$ 16.1, where $M_{0}$ is the seismic moment in dyne-cm and $M_{L}$ is the local 
magnitude (Thatcher and Hanks, 1973). In this calculation, we included all the aftershocks with magnitudes $\left(M_{\text {mainshock }}{ }^{-3.5}\right.$ ) or larger that occurred within 1 yr after the mainshock. For the Loma Prieta earthquake (18 October 1989) and the Upland earthquake (28 February 1990), we included the aftershocks that occurred during the $2 \mathrm{wk}$ and 6 months after the mainshock, respectively. The results thus obtained are listed in Table 2.

Figure 6 plots $\log \sum M_{0 A}$ against $\log$ of the mainshock moment, $M_{0 M}$, for these events. The solid lines indicate the trend for constant ratios, $1,1 / 10^{2}$, and

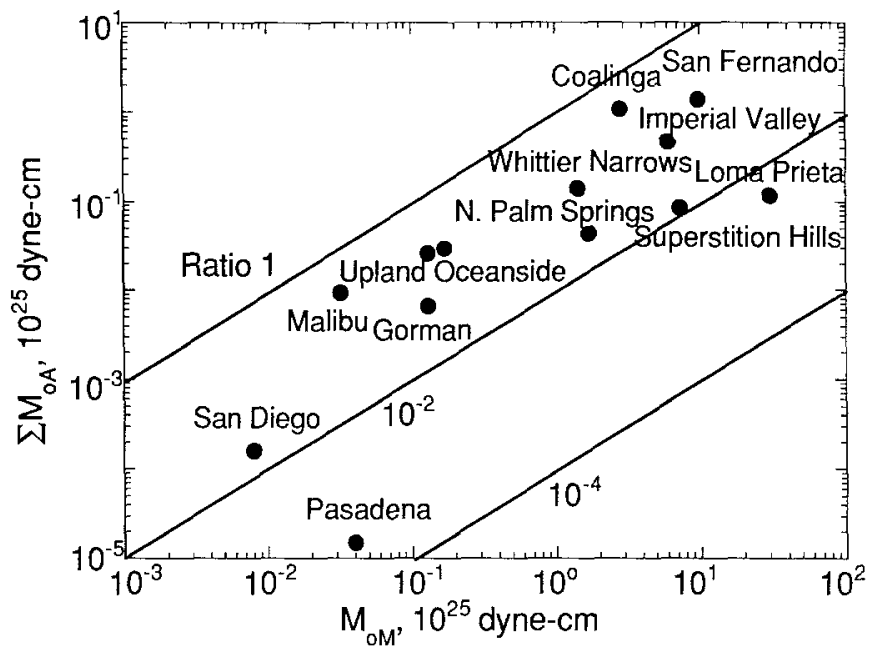

FIG. 6. Logarithm of cumulative aftershock seismic moment plotted as a function of logarithm of the seismic moment of the main shock for San Fernando $\left(M_{L}=6.4\right)$, 1971; Imperial Valley $\left(M_{L}=6.6\right)$, 1979; Coalinga $\left(M_{L}=6.3\right)$, 1983; San Diego $\left(M_{L}=4.6\right), 1983$; North Palm Springs $\left(M_{L}=5.9\right), 1986 ;$ Oceanside $\left(M_{L}=5.4\right), 1986 ;$ Superstition Hills $\left(M_{L}=6.1\right), 1987$; Whittier Narrows $\left(M_{L}=5.9\right), 1987$; Gorman $\left(M_{L}=5.4\right)$, 1988; Pasadena $\left(M_{L}=4.9\right)$, 1988; Malibu $\left(M_{L}=\right.$ 5.0), 1989; Loma Prieta $\left(M_{L}=6.9\right), 1989$; and Upland $\left(M_{L}=5.2\right), 1990$ earthquake sequences. The solid lines indicate ratios of $1,1 / 10^{2}$, and $1 / 10^{4}$.

TABLE 2

The Seismic Moment of the Mainshock, and the Sum of the Seismic Moment of the AFtershocks For 13 EARTHQUAKE SEQUENCES IN CALIForNia

\begin{tabular}{|c|c|c|c|c|}
\hline Event & Date & $M_{L}$ & $\begin{array}{c}M_{\mathrm{OM}}^{*} \\
\left(10^{25} \text { dyne-cm) }\right.\end{array}$ & $\begin{array}{c}\sum M_{\mathrm{OA}} \\
\left(10^{23} \text { dyne-cm }\right)\end{array}$ \\
\hline San Fernando & $71 / 02 / 09$ & 6.4 & 9.75 & 139.00 \\
\hline Imperial Valley & $79 / 10 / 15$ & 6.6 & 6.00 & 46.50 \\
\hline Coalinga & $83 / 05 / 02$ & 6.3 & 2.82 & 108.00 \\
\hline San Diego & $03 / 06 / 29$ & 4.6 & 0.008 & 0.016 \\
\hline North Palm Spring & $86 / 07 / 08$ & 5.9 & 1.70 & 4.35 \\
\hline Oceanside & $86 / 07 / 13$ & 5.4 & 0.13 & 2.64 \\
\hline Whittier Narrows & $87 / 10 / 01$ & 5.9 & 1.43 & 14.05 \\
\hline Superstition Hills & $87 / 11 / 24$ & 6.1 & 7.20 & 8.50 \\
\hline Gorman & $08 / 06 / 10$ & 5.4 & 0.13 & 0.67 \\
\hline Pasadena & $88 / 12 / 03$ & 4.9 & 0.04 & 0.0015 \\
\hline Malibu & $89 / 01 / 19$ & 5.0 & 0.032 & 0.95 \\
\hline Loma Prieta & $89 / 10 / 18$ & 6.9 & 30.0 & 11.70 \\
\hline Upland & $90 / 02 / 28$ & 5.2 & 0.17 & 2.97 \\
\hline
\end{tabular}

*Average of the published values. 
$1 / 10^{4}$. Except for the Pasadena earthquake sequence, all the sequences have a ratio between 1 and $1 / 100$. The ratio for the Pasadena earthquake sequence is about $1 / 1000$ and is distinctly lower than the others.

Recent studies (e.g., Mendoza and Hartzell, 1988; Schwartz et al., 1989; Choy and Dewey, 1988) show that aftershocks generally do not occur in the regions where the mainshock slip is large. Houston and Engdahl (1989), in their study of the 1986 Andreanof Islands earthquake, found that the moment release of the mainshock occurred in regions of no or few aftershocks or preshocks. They suggest that the most moment release occurs from strong regions on the fault plane that are locked before or after the mainshock. Kanamori et al. (1990) found that most of the mainshock energy of the Pasadena earthquake came from two strong asperities on the fault plane. We suggest that, before the mainshock, the strain had accumulated there without producing any seismic events; during the mainshock almost all the energy was released in a high-stress drop event, leaving little energy for aftershocks.

\section{ConClusions}

We determined the focal mechanisms of the Pasadena earthquake sequence by applying an inversion method to the waveform data. The first-motion data are combined in a systematic way with the waveform data to determine mechansims that are consistent with both sets of data. The aftershock mechanisms are, overall, consistent with left-lateral strike-slip motion on the Santa Monica-Raymond fault, which is consistent with the result of Jones et al. (1990). The small ratio of the cumulative aftershock seismic moment to the mainshock seismic moment of the Pasadena earthquake is consistent with the high-stress drop model, in which most of the energy was released from strong asperities.

\section{ACKNOWLEDGMENTS}

This work was partially supported by the USGS grant 14-08-0001-G1774. Contribution no. 4943, Division of Geological and Planetary Sciences, California Institute of Technology, Pasadena, California.

\section{REFERENCES}

Choy, G. L. and J. W. Dewey (1988). Rupture process of an extended earthquake sequence: teleseismic analysis of the Chilean earthquake of March 3, 1985, J. Geophys. Res. 93, 1103-1118.

Houston, H. and E. R. Engdahl (1989). A comparison of the spatio-temporal distribution of moment release for the 1986 Andreanof Islands earthquake with relocated seismicity, Geophys. Res. Lett., 16, 1421-1424.

Jones, L. M., K. E. Sieh, E. Hauksson, and L. K. Hutton (1990). The 3 December 1988, Pasadena, California, earthquake: evidence for strike-slip motion on the Raymond fault, Bull. Seism. Soc. Am. 80, 474-482.

Kanamori, H. (1989). Pasadena very-broad band system and its use for realtime seismology, extended abstract for the U.S.-Japan Seminar for Earthquake Research, Morro Bay, California, 11-15 September 1988, U.S. Geol. Surv. Open-File Rept. 90-98.

Kanamori, H., J. Mori, and T. H. Heaton (1990). The 3 December 1988 Pasadena earthquake $(M=4.9)$ recorded with the very broadband system in Pasadena, Bull. Seism. Soc. Am. 80 $483-487$

Magistrale, H. W. (1990). Three-dimensional velocity structure of southern California, Pasadena, California Institute of Technology, Ph. D. Thesis, $294 \mathrm{pp}$.

Mendoza, C. and S. H. Hartzell (1988). Aftershock patterns are mainshock faulting, Bull. Seism. Soc. Am. 78, 1438-1449. 
Reasenberg, P. and D. Oppenheimer (1985). FPFIT, FPPLOT, and FPPAGE: Fortran computer programs for calculating and displaying earthquake fault-plane solutions, U.S. Geol. Surv. Open-File Rept. 85-739.

Schwartz, S. Y., J. W. Dewey, and T. Lay (1989). Influence of fault plane heterogeneity on the seismic behavior in the Southern Kuriles Islands arc, J. Geophys. Res. 94, 5637-5649.

Thatcher, W. and T. C. Hanks (1973). Source parameters of southern California earthquakes, $J$. Geophys. Res. 78, 8547-8576.

Seismological LaboRatory 252-21

California Institute of Technology

Pasadena, California 91125

Manuscript received 13 November 1990 